\title{
The Moderating Effect of Different Types of Internet Use on the Relationship between Transitional Aging Changes and Self-Esteem of Older Adults
}

\author{
Gabriel Chun-Hei LAI \\ City University of Hong Kong \\ gabrilai2-c@my.cityu.edu.hk
}

Alvin Chung-Man LEUNG

City University of Hong Kong

acmleung@ cityu.edu.hk

\author{
Ron Chi-Wai KWOK \\ City University of Hong Kong \\ isron@cityu.edu.hk \\ Yanyan LI \\ City University of Hong Kong \\ yanyali3-c@ cityu.edu.hk
}

\author{
Tina ROCHELLE \\ City University of Hong Kong \\ rochelle@cityu.edu.hk \\ Shanshan ZHANG \\ Zhejiang University of \\ Technology \\ zss_200890@126.com
}

\author{
George Yui-Lam WONG \\ City University of Hong Kong \\ georgew.bauhaus@yahoo.com.hk
}

\author{
Angel LU \\ City University of Hong Kong \\ angellu@ cityu.edu.hk
}

\begin{abstract}
This study investigates the moderating effect of different types of Internet use regarding the relationship between three transitional aging changes and self-esteem of older adults. The current paper is still in progress; this is a research-in-progress paper. An aging population increases government expenditures and family responsibilities, thus drawing more attention from the academic community. Recent research posits that self-esteem tends to decline in individuals from the ages around 50-65 due to role loss, social loss, and dissatisfaction resulting from unaccomplished life goals. To address this issue, previous studies considered that the general use of the Internet may help to enhance self-esteem among older adults. To fill this research gap, the present study proposes that the cultural use of the Internet could moderate role loss of older adults, while social use of the Internet could mitigate social loss. Furthermore, economic use could moderate the dissatisfaction of unfulfilled life goals. Regarding various theoretical contributions, this is the first study to apply different types of Internet use, so as to investigate its moderating effect concerning the relationship between transitional aging changes and self-esteem. Findings of the present study can also help shed light on interventions for the caregiver in both community centers and the domestic environment to moderate the decline of self-esteem among older adults. The data will be collected through surveys distributed to District Elderly Community Centers (DECCs) in Hong Kong. Multiple regression analysis will then be utilized to test the moderating effect of each type of Internet use.
\end{abstract}

\section{Introduction}

As the older adult population has experienced extensive growth over the last few decades, more researchers are interested in research focusing on these seniors. The population of the so-called "Baby Boomers," who were born between 1946 and 1964, is rapidly approaching retirement age, and life expectancies continue to grow due to the advancement of medical technology which is sustaining the health of older adults [3]. As the older adult population expands, more resources and support are needed from the government or community to assist older adults [58]. For example, more resources are required from the healthcare industries, and increasingly more healthcare professionals are in demand to deal with elderly patients due to the deterioration of their physical condition [37]. The overall economic health of society may also be affected as most older adults retire, thereby decreasing their productivity and contribution to society, while, at the same time, consuming resources such as old age assistance from the government [24]. Therefore, more attention has been focused on older adult studies.

Psychological well-being is one of the main focuses of this type of research. More specifically, regarding self-esteem, an individual undergoes tremendous transitional changes from adulthood to old age [40]. Furthermore, there is a gradual increase in individuals' self-esteem during adulthood until the age of approximately 65 , which appears to be the general turning point when self-esteem tends to decline sharply. The decline of self-esteem may negatively 
affect the psychological well-being of older adults, since self-esteem and psychological well-being are empirically related [35]. Moreover, some studies posit that this condition may even have an earlier onset. Reference [33] determined that self-esteem begins dropping at the age of 60 . Later, a few more studies found that self-esteem starts to decline at 50 [31], [32]. Therefore, the decline of self-esteem seemed to occur earlier in recent years, which implies that self-esteem associated with old age is beginning to decline at a younger age than previously thought. Reference [32] also showed that negative outcomes, such as depression, coincide with a drop in self-esteem. Also, reference [34] found that low self-esteem is one of the risk factors for depressive symptoms during all phases of the adult life span. Thus, the decrease in self-esteem is worth being discussed and further researched.

According to the [57], over $20 \%$ of the adults aged 60 and over suffer from one or more types of mental disorders. Depression is one of the major mental health disorders that strike the older population. In Hong Kong, three out of 100 adults suffer from depression, and one out of 10 senior citizens have depressive symptoms [50]. Another local study found that seniors who exhibit depressive symptoms had a 2.2 times higher risk of suicide mortality than those without [49]. Thus, mental health and psychological well-being are important for older adults to attain successful aging [42]. According to [50], it is of paramount importance to maintain mental health, since mental health problems can lead to serious negative behaviors, including substance abuse and suicide. Older adults with such conditions may also become a burden to his or her family [43]. Older adults with mental health diseases or depression may be more difficult to handle by caregivers, resulting in an even more stressful work environment for the caregiver and, thus, increase the turnover rate of these care providers [1]. From a governmental perspective, extensive support and expenses for mental healthcare are needed. For example, counseling services may be included in elderly care centers, or old age homes and other expenses include hiring mental health care professionals and providing more training for care staff [24].

A declining functional capability and cognitive function may also lower the perceived self-worth of the elderly. Reference [26] postulated that the deterioration of both physical and cognitive functions contributes to the development of depression and other mental problems, which could potentially cause social withdrawal. This would include a withdrawal from roles and activities such as work and other responsibilities, or it might even bring about suicidal behavior. Thus, the loss of role and social engagement may result in a declining sense of personal importance, self-perceived usefulness, and competence. Reference [2] posited that these negative experiences may very well be a contributing factor causing a diminishing self-esteem. Because self-esteem and psychological well-being are empirically related [35], improving selfesteem among the older population may possibly help seniors maintain or enhance their psychological wellbeing, thereby lowering their chance of suffering from depression or other mental health-related problems. Hence, role development [5] and social engagement [28] are critical for psychological well-being. One of the major therapies for treating low self-esteem individuals is cognitive-behavioral treatment (CBT). Reference [53] conducted a randomized controlled trial and found positive outcomes after treating low selfesteem patients. CBT for low self-esteem patients was proposed by [12] and has been widely adopted in social science and psychology research. Due to technological advancements, many technologies come into play when assisting older adults; these technologies that facilitate successful aging in seniors is called "gerontechnology" [4]. Information and communication technologies have become one of the major modes of gerontechnology, yet it has not received much attention when considering it as a treatment or intervention protocol for low selfesteemed older adults.

Internet use has become a very important part of most peoples' lives, from childhood to old age, due to the rapid advancement of technology. Moreover, [59] reported that $53 \%$ of American adults aged 65 and older use the Internet or email. In other words, older adults are using the Internet nowadays and are more familiar with Internet usage; thus, Internet use should be considered a viable tool for intervention. Reference [47] conducted an online survey and found that Internet use was associated with a lower level of social loneliness. Later, [48] also addressed that Internet usage was positively associated with well-being and life satisfaction. Reference [46] also mentioned that Internet use can significantly decrease loneliness and depression, as well as enhancing one's self-esteem. Hence, a significant number of positive psychological effects were found to be associated with Internet use. Furthermore, previous studies have also revealed a direct positive correlation between Internet use and self-esteem as one construct.

However, two research gaps have been identified in this study. First, the effect of different types of Internet use regarding the relationship of transitional changes in aging and self-esteem is unclear. Furthermore, the measurement for Internet use that researchers used in the previous studies included general Internet usage such as, the total time spent online and the frequency 
of Internet use. A relatively more specific measurement includes dividing Internet use into social and instrumental use [19]. However, a more concise and systematic measurement for Internet use is required to help researchers comprehend the effects of different types of Internet use with regard to the older adult population. Second, most older adults experience a decline in self-esteem when they reach the age of 5065 , but some of them increased their self-esteem after this turning point. However, thus far, this difference has not received much attention. Additionally, limited research has attempted to explain why some older adults have an increase in self-esteem while some do not. In this study, we take into consideration the different types of Internet use as a moderator in the relationship between age and self-esteem of older adults. The study is still in progress; this is a researchin-progress paper. In addition, the current study aims to investigate whether different types of Internet use can moderate the causes of a decrease in self-esteem and how these may increase or decrease the self-esteem in the older adult population. Hence, we propose that diverse types of Internet use may have different effects; some types of Internet use may bring about a positive moderating effect, while others may reflect a negative moderating effect. The present study is the first research to apply the three of the four types of Internet use [18] (i.e., economic use, cultural use, and social use) to investigate its moderating effect on the three transitional changes of aging.

\section{Theoretical Framework and Hypotheses}

\subsection{Self-esteem}

Reference [31] defined self-esteem as an individual's subjective evaluation of his or her worth as a person, and is a term used to reflect a person's overall evaluation or appraisal of his or her own worth [53]. According to [40], there are some fluctuations in self-esteem across one's lifespan which could be due to changes in our social environment as well as maturational changes such as puberty and cognitive declines in old age. The focal point of the present study is the decrease in self-esteem associated with transitional aging changes. This decline may be due to the dramatic changes that occur in old age, including changes in roles (e.g., retirement), social support (e.g., the loss of a spouse), and functional capability (e.g. physical and cognitive problems) [39]. The old-age decline in self-esteem may also reflect a shift toward the negative tendency in the eighth stage of psychosocial development such as despair, which indicates a dissatisfaction of a person's unaccomplished life goals [11]. As mentioned in the introduction, low self-esteem in older adults leads to various kinds of problems such as increased family burdens and responsibilities [43], mounting government expenditures [24], and an escalated turnover rate for caregiving [1]. Furthermore, selfesteem is significantly important to an individual, especially for older adults. According to [30], selfesteem is related to one's dignity, achievement, and self-respect. Reference [30] posited that self-esteem is a precursor of the development of self-actualization, which is highly related to successful aging [58].

\subsection{Internet Use}

According to [18], Internet use can be categorized into four fields: economic, cultural, social, and personal. Reference [18] defined the economic use of the Internet as selling something online, job seeking, or looking for education and learning opportunities to improve one's job prospects. However, the cultural use of the Internet is viewed more as a cultural resource, like understanding the value of entertainment as shared norms that guide behavior and give meaning to belonging and identity to a certain group. Additionally, social use of the Internet is regarded as looking for online information concerning clubs and societies, participating in discussions that influence the local community, or interacting with people who share similar interests. Lastly, personal use of the Internet includes activities achieved by individuals independently and is not organized, such as more formal or informal organizational structures. Thus, it is important to note that the classification of Internet use is focused on the outcome of Internet use, and not classifying the function itself. For instance, an older adult joins a religious group or community on social media in order to receive the most up-to-date information regularly of the group but does not socialize with other members in the group; this should be considered as cultural use even though it is on a social platform. However, in the present study, only three types of Internet use will be discussed, which we believe will moderate the negative relationship between the three transitional changes of aging and self-esteem.

The four types of Internet use classification from [18] are less general and were conceptualized with theoretical support. Referring to literature summarized by [18] regarding the uses of information and communication technologies, the various activities through Internet use can be classified as entertainment and leisure, information and learning, communication and interaction, commercial and financial, creative and productive, and participation and engagement 
resources. Moreover, the above Internet uses were concluded according to a theory derived from the communication field, known as the uses and gratifications theory. The uses and gratifications theory was introduced by [41], which addressed that the communication needs of a person and his or her social and psychological factors actually combined to produce the motives for media use. This simply means that people use information and communication technologies based on their purposes and they select appropriate media that matches their purpose or their specific needs or goals [8]. Next, [18] applied this kind of classification regarding Internet use to the theory of forms of capital.

According to [18], assets or resources of individuals can be classified into three perspectives, including economic, cultural, and social. Economic capital refers to assets or resources that can be immediately converted into cash or property rights in institutions, while cultural capital indicates the education or qualifications that an individual has achieved, while social capital denotes one's connections and networks. Combining the uses and gratifications theory and the theory of forms of capital to the types of Internet use, the four types of Internet use (economic, cultural, social, and personal) summarized most, if not all, of the activities online with a balanced amount of theoretical support and conceptualization. Because of this, the present study will apply this categorization of Internet use to effectively measure the Internet use of the participants and investigate the moderating effects of the different types of Internet use as concerning the relationship between age and self-esteem.

\subsection{Role loss and Self-esteem}

Findings from [36] and [54] also echoed that along with the diminishing self-esteem in the older adult population, there seem to be more health-related problems and declining achievement experiences following retirement. Reference [26] believed that the deterioration of both physical and cognitive functions contributes to role loss, social loss, and a dissatisfaction regarding unaccomplished life goals. According to role theories, this type of role loss from society or community is quite stressful and difficult for the elderly to handle [5]. The loss of role, power, and achievement may, therefore, result in a pessimistic view of an individual as well as a declining sense of personal importance, self-perceived usefulness, and competence, which results in a lowering self-esteem.

Reference [40] suggested the loss of role as another cardinal explanation for the turning point in older adults' self-esteem. The loss of role in old age may result in a diminishing sense of personal importance and self-esteem [5]. According to [18], the cultural use of the Internet is related to identity construction or affirmation (e.g., use of the Internet to explore feminism) and supports a feeling of belonging to a particular group (e.g., using the Internet for religion or to support parenting). Thus, we propose that the loss of role in older adults can be re-developed through more specific Internet use by referring to the cultural use of the Internet, which is when an individual pursues internal rewards such as spiritual well-being, identity, and belonging [18]. According to the gerotranscendence theory [51], aging individuals undergo a cognitive transformation from materialistic to humanistic, and emphasize a more substantive relationship, sense of connectedness, or spiritual unity with the universe. On the other hand, the socioemotional selectivity theory [6] suggests that older adults tend to select or invest greater resources in emotionally meaningful events such as interpersonal relationships. Considering the views mentioned above, older adults tend to re-develop their roles based on cultural and spiritual perspectives in order to achieve enhanced psychological well-being. In addition to the definition of the cultural use of the Internet, it is also related to a sense of belonging and identity, which are both highly related to the gerotranscendence theory and socioemotional selectivity theory. Regardless of the independent effect from role loss to self-esteem, we believe that the negative relationship between role loss and self-esteem is moderated by cultural Internet use in so much that the relationship diminishes when older adults use the Internet for cultural purposes such as identity construction or affirmation and the development of a sense of belonging. An example for this use would be joining a religious group (e.g. Buddhist community) on social media platform, communicating and exchanging information related to the group and develop the sense of belonging and identity (i.e. a member of the Buddhist community). Therefore, based on the views mentioned, the following hypothesis was formed:

H1: The effect of role loss on self-esteem depends on the level of cultural use of the Internet.

\subsection{Social loss and Self-esteem}

In gerontology, the activity theory of aging [17] suggests that it is necessary for older adults to remain occupied and actively engage in life to have a satisfying late in life experience and maintain their psychological health in order to attain successful aging [42]. Because older adults are deteriorating physically and mentally, they lose their abilities to keep informed or updated about the world and appear to socialize less 
[10]. Fortunately, these days, the Internet acts as a medium for them to remain active and interact with the world. For example, online text messages and video calls allow older adults to maintain a certain level of social connection with friends and family, while social networking sites can provide various forms of information to keep older adults updated. In addition to the activity theory, [28] further emphasized that having a social element in activities is critical for general psychological well-being. For example, having a group discussion about a book is more conducive than reading books alone to help maintain one's psychological well-being.

Some literature [31], [32], [40] pointed out a sudden plummet in self-esteem when people reached the age of around 50-65. One of the reasons for the deterioration of self-esteem is the loss of social support. Most of the research was also in support of Internet usage being able to enhance social activities and, thus, lowering a person's social loneliness [46], [47]. Meanwhile, plenty of other research conceded that lonely individuals tend to score lower in selfesteem, or even self-actualization [45], which are both essential for human beings [30]. Moreover, [55] determined that older adults with integrated social support networks are more likely to be less depressed and report a more profound sense of well-being. Therefore, by adapting the concept of social connectedness, older adults who maintain contact with friends and family and keep themselves up-to-date, tend to exhibit a higher level of self-esteem and psychological well-being [25]. Recalling the concept of the activity theory of aging, [28] emphasized that the social participation element is rather important. They addressed the fact that older adults involved in activities with a social element scored higher in life satisfaction than those who were involved in activities with no social element at all. Therefore, older adults who are involved in social participation enjoy a higher level of psychological well-being. Regardless of the independent effect from social loss to self-esteem, we believe that the negative relationship between social loss and self-esteem can be mitigated by social Internet use to such an extent that this correlation diminishes when older adults use the Internet for social purposes like connecting with friends and family members, broadening their social circle, or even developing new networks. Therefore, based on the views mentioned, the following hypothesis was formed:

$\mathrm{H} 2$ : The effect of social loss on self-esteem depends on the level of social use of the Internet.

\subsection{Erikson's stage theory of psychosocial development and Self-esteem}

Erik Erikson formulated a psychosocial theory of eight stages concerning personality development, each with its own psychosocial crisis that arises out of a conflict between two opposite tendencies [44]. There are two tendencies, positive and negative. The successful resolution of each conflict leads to enhanced developmental strength in terms of a new virtue. The eight stages of psychosocial development that [11] introduced are as follows: trust (vs. mistrust); autonomy (vs. shame); initiative (vs. guilt); industry (vs. inferiority); identity (vs. confusion); intimacy (vs. isolation); generativity (vs. stagnation); and ego integrity (vs. despair). The current study focuses on stage eight, which is related to older adults.

Throughout the human lifespan, there are eight stages of psychosocial development, as suggested by [11]. The last stage of the human lifespan is labeled "ego integrity versus despair". People at this stage tend to contemplate and evaluate their own accomplishments and thus develop integrity. If an individual fails to accomplish his or her goals in life or is dissatisfied with his or her life, the individual will develop despair. Having the dissatisfaction of unaccomplished life goals leads to an unbalanced view of the self that gives rise to the negative tendency of the eighth stage of Erikson's stage theory- despair, that eventually lowers the self-esteem of older adults.

As mentioned above, one of the reasons for the decline in self-esteem may result from individuals who are unable to accept the fact that they are getting old, are unable to accomplish life goals, and are dissatisfied with their lives [40]. Among the four types of Internet use [18], the economic aspect mainly pursues external rewards such as money, which may lead to the dissatisfaction developed in older adults. An assumption was made here that economic Internet users tend to be extrinsically reward-oriented and more materialistic. According to [18], economic Internet users tend to utilize the Internet for financial services and banking or shopping online. In other words, the more the older adult uses the Internet for economic purposes, the more he or she is surrounded by economic activities. This implies that he or she is inclined to favor a materialistic world, instead of humanistic, thereby opposing the theory of gerotranscendence [51]. On the other hand, [23] conducted a study that demonstrated that materialism is associated with lower self-esteem. Some research studies also received negative psychological outcomes, such as lower life satisfaction, depression, and unhappiness [52]. Additionally, the materialisticeconomic Internet users tend to pursue extrinsic rewards restlessly, which tend to leave them with a sense of feeling dissatisfied. Therefore, economic Internet users are more likely to fall into the "despair" 
side according to the Erikson's stage theory of psychosocial development [11]. In that sense, economic Internet users are more materialistic as compared with the other types of Internet users, and the feeling of dissatisfaction may contribute to developing despair, which, in turns, lowers one's selfesteem.

Regardless of the independent effect that a dissatisfaction of unaccomplished life goals can have on self-esteem, we believe that the negative relationship between dissatisfaction and self-esteem was moderated by economic Internet usage such that the relationship amplified when older adults use the Internet for economic purposes such as making various kinds of investments online. Therefore, based on the views mentioned above, the following hypothesis was formed:

H3: The effect of dissatisfaction on self-esteem depends on the level of economic use of the Internet.

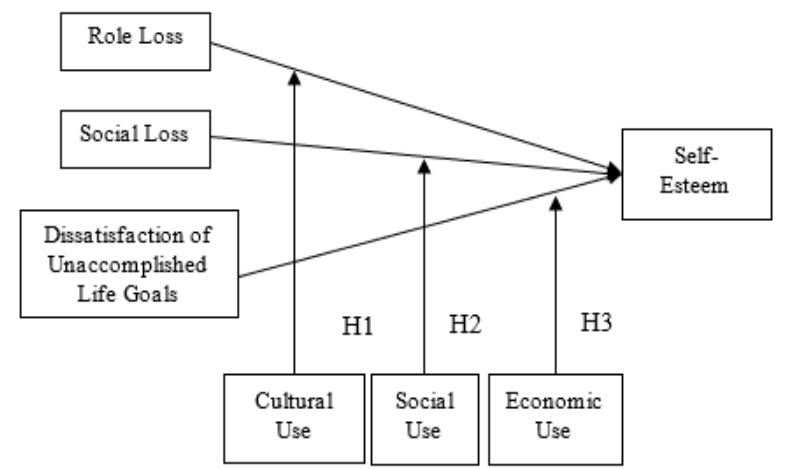

Figure 1. The Research Model showing types of Internet use as moderator in the relationship between the three transitional aging changes and self-esteem.

Overall, due the fact that only three transitional aging changes were identified, the present study is aimed at investigating the diverse moderating effects of the above three types of Internet usage on the relationship between transitional aging changes and self-esteem of older adults. This model has four control variables - gender, educational level, and economic status. which are expected to influence self-esteem [7].

\section{Research Design and Approach}

The aim of the present study is to explore how the different intents of using the Internet mitigate the negative effect of aging on self-esteem in the senior population. The target subjects are individuals aged fifty or older. According to findings from research conducted by [40], self-esteem drops markedly at the age of sixty-five. However, [31] suggested the decline starts earlier, at the age of fifty. We are interested in the effect of various kinds of Internet usage on the selfesteem level of older adults and whether it can moderate the decrease in the self-esteem level of older adults, or even improve that of older adults after experiencing a drop in self-esteem. Therefore, we have decided to measure the self-esteem of older adults age fifty years and above, since it would allow us to observe any self-esteem changes after a substantial drop in self-esteem which began at the age of fifty.

We propose to do a survey for this study. Concerning the questions pertaining to the different types of Internet usage, we adapted Measuring Types of Internet Use [18], which categorized Internet use into four fields: economic, cultural, social, and personal, and covered a wide range of types of Internet use. After some relevant adjustments, we narrowed the initial questionnaire down to an 9-item questionnaire to measure Internet use in our study. In the present study, only three types of Internet use were accessed (economic, cultural, and social) as we only hypothesized that these three types of Internet use can moderate the negative relationships between the three transitional aging changes and self-esteem. The questions regarding the self-esteem in older adults were adapted from the Bachman Revision of Rosenberg's Self-Esteem Scale [36]. Since it was designed to assess the self-esteem of older adults, we directly applied the 10-item questionnaire into our study. Moving on to independent variables, role variable consist of employment status (employed and unemployed), marital status (married, never married, widowed, and divorced), and health perceptions (excellent, good, fair, and poor) [14]. People who are unemployed, being divorced or widowed, and poor health were considered as "role loss." For social loss, the present study adapted the measurement from study conducted by [27]. Reference [27] social support for older adults using a 12-item modified Medical Outcomes Study Social Support Survey which based on three constructs: material support, emotional support, and positive social interaction. For measuring the tendency of the eighth stage of Erikson's theory, the current study applied the measurement from the study conducted by [15]. The measurement included 15-item to measure the tendency of ego integrity versus despair.

\subsection{Data Collection}

Data for the present study will be gathered from District Elderly Community Centers (DECCs) in various districts in Hong Kong; thus, the participants will also be recruited from DECCs [7]. The age range of the participants is expected to be between fifty or above. Furthermore, the materials used in the present 
study are the 9-item modified questionnaire titled Measuring Types of Internet Use [18] for Internet use assessment and the 10-item Bachman Revision of Rosenberg's Self-Esteem Scale [36] to assess the selfesteem levels of the participants. In addition, role variable, including employment status, marital status, and health perceptions, are measured. Social support and tendency of Erikson stage theory are measured as well. Socio-demographic information will also be collected for analysis, including gender, and education level, which will also serve as control variables.

\subsection{Data Analysis}

In order to test the moderating effect, a multiple regression analysis will be performed utilizing one base model; the predictive variables will include age, gender, and education level where the dependent variable is self-esteem. The moderating effects will be evaluated by utilizing three regression models by adding economic, cultural, or social Internet use subscale scores and an interaction term between three transitional aging changes and the corresponding type of Internet use [9].

The empirical model adapting regression is as follows: Self-esteem $=\beta 0+\beta 1 \mathrm{SU}+\beta 2 \mathrm{EU}+\beta 3 \mathrm{CU}+\beta 4 \mathrm{RL}+$ $\beta 5 \mathrm{SL}+\beta 6 \mathrm{DL}+\beta 7 \mathrm{CV}+\varepsilon$

(Where PU= Personal use; $\mathrm{SU}=$ Social use; $\mathrm{EU}=$ Economic Use; $\mathrm{CU}=$ Cultural Use; $\mathrm{RL}=$ Role Loss; SL = Social Loss; DL = Dissatisfaction of Life; $\mathrm{CV}=$ Control Variables)

\section{Outlook and Conclusion}

In conclusion, the study intends to investigate how different types of Internet use mitigate the negative effect of transitional aging changes on self-esteem in older adults in Hong Kong. The present study adapted five measuring tools from previous literature to measure the various types of Internet use alongside the self-esteem of seniors.

Regarding the expected theoretical contribution, it will be the first research to apply the three of the four types of Internet usage [18] to investigate its moderating effect regarding the relationships between transitional aging changes and self-esteem. It is also the first study to address whether cultural usage of the Internet has a positive moderating effect on the association between the three transitional aging changes and self-esteem in terms of a role-loss perspective. It would appear that the social use of the Internet has a positive moderating effect on self-esteem in terms of social loss. Economic use of the Internet has a negative moderating effect on self-esteem in terms of dissatisfaction of unaccomplished life goals. Moreover, results from the social Internet use can be utilized to support the activity theory of aging which emphasizes that social participation plays an essential role in successful aging [27] and [42]. Therefore, the present study can provide evidence to support the activity theory in an online medium. Additionally, the results of cultural role development can determine what type of Internet use Hong Kong seniors are more likely to engage in and whether it is consistent with the socioemotional selectivity theory [6] and the gerotranscendence theory [51] which proffer that older adults are more likely to engage in cultural Internet usage for inner personal development. Furthermore, results from the economic use of the Internet can provide evidence to support the assumption of materialism and the extrinsic goal orientation of economic-driven Internet users. It can also shed light on the application of Erikson's stage theory of psychosocial development on Internet usage and selfesteem research.

As pertaining to the expected practical contribution, the findings of the study can promote diverse types of Internet use to achieve different outcomes for the general public. Thus, it can be considered as a type of primary prevention when it comes to a decline in selfesteem. Older adults around the ages of 50 to 65 are encouraged to engage in the cultural and social use of the Internet to prevent or postpone their decline of selfesteem, whereas economic use of the Internet is discouraged since it may cause a deterioration of selfesteem. The findings of the study can also shed light on intervention for caregivers in both community centers and the domestic environment to mitigate the decline of self-esteem of older adults. Finally, the cultural and social use of the Internet can also act as an intervention tool for older adults with low self-esteem or those suffering from depression or other mental disorders.

\section{References}

[1] Albert, S. M., Brassard, A. B., Simone, B., \& Stern, Y. (2004). Older Adults' Reports of Formal Care Hours and Administrative Records. The Gerontologist, 44, 186-192.

[2] Baltes, P. B., \& Mayer, K. U. (Eds.). (1999). The Berlin Aging Study: Aging from 70 to 100. Cambridge, England: Cambridge University Press.

[3] Bloom, D. E., Boersch-Supan, A., McGee, P., \& Seike, A. (2011). Population Aging: Facts, Challenges, and Responses. Program on the Global Demography of Aging. 
[4] Bronswijk, J. E. M. H., Bouma H., Fozard, J. L., Kearns, W. D., Davison, G. C., \& Tuan, P. (2009). Defining gerontechnology for R\&D purposes. Gerontechnology, 8, 310. doi: $10.4017 /$ gt.2009.08.01.002.00

[5] Bush, D. M., \& Simmons, R. G. (1981). Socialization process over the life course. In M. Rosenberg \& R. Turner (Eds.), Social psychology: Sociological perspectives (pp. 133-164). New York: Basic.

[6] Carstensen, L. (1995). Evidence for a life-span theory of socioemotional selectivity. Current Directions in Psychological Science, 4, 151-156.

[7] Chen, K., \& Chan, A. H. S. (2014). Gerontechnology acceptance by elderly Hong Kong Chinese: a senior technology acceptance model (STAM), Ergonomics, 57:5, 635-652, DOI: 10.1080/00140139.2014.895855

[8] Cho, J., De Zuniga, H. G., Rojas, H., \& Shah, D. V. (2003). Beyond Access: The Digital Divide and Internet Uses and Gratifications. IT \& Society, 1, 46-72.

[9] Chou, K-L., \& Chi, I. (2002). Financial strain and life satisfaction in Hong Kong elderly Chinese: Moderating effect of life management strategies including selection, optimization, and compensation, Aging \& Mental Health, 6:2, 172-177, DOI: 10.1080/13607860220126781

[10] Cornwell, Benjamin, Edward O. Laumann, and L. Philip Schumm. 2008. "The Social Connectedness of Older Adults: A National Profile.” American Sociological Review, 73:185203

[11] Erikson, E. H. (1968). Identity, youth, and crisis (1st ed.). New York: W. W. Norton.

[12] Fennell, M. J. V. (1998). Cognitive therapy in the treatment of low self-esteem. Advances in Psychiatric Treatment, 4, 296-304.

[13] Gao, Q., D. Ebert, X. Chen, and Y. Ding. 2012. "Design of a Mobile Social Community Platform for Older Chinese People in Urban Areas." Human Factors and Ergonomics in Manufacturing 19 (6): 1-24. doi:10.1002/hfm.20523.

[14] Gove, W. R., Ortega, S. T., \& Style, C. B. (1989). The Maturational and Role Perspectives on Aging and Self through the Adult Years: An Empirical Evaluation. American Journal of Sociology, 94, 1117-1145.

[15] Hannah, M. T., Domino, G., Figueredo, A. J., \& Hendrickson, R. (1996). The Prediction of Ego Integrity in Older Persons. Educational and Psychological Measurement, 56, 930-950.

[16] Hartson, H. R. (1998). Human-computer interaction: Interdisciplinary roots and trends. Journal of Systems and Software, 43, 103-118.
[17] Havighurst, R. J., \& Albrecht, R. (1953). Older people. New York: Longmans

[18] Helsper, E.J., van Deursen, A.J.A.M. \& Eynon, R. (2016). Measuring Types of Internet Use. From Digital Skills to Tangible Outcomes project report. Available at: http://www.lse.ac.uk/media@1se/research/From-digitalskills-to-tangible-outcomes.aspx

[19] Huang, C. (2010). Internet use and psychological wellbeing: A Meta-Analysis. Cyberpsychology, behavior, and social networking, 13,241-29. DOI:

$10.1089=$ cyber.2009.0217

[20] Jaquish, G. A., \& Ripple, R. E. (1981). Cognitive creative abilities and self-esteem across the adult life-span. Human Development, 24, 110- 119.

[21] Jeong, K. A., G. Salvendy, and R. W. Proctor. 2010. "Smart Home Design and Operation Preferences of Americans and Koreans." Ergonomics 53 (5): 636-660.

[22] Kahlbaugh, P. E., Sperandio, A. J., Carlson, A. L., \& Hauselt, J. (2011). Effects of Playing Wii on Well-Being in the Elderly: Physical Activity, Loneliness, and Mood, Activities, Adaptation \& Aging, 35:4, 331-344, DOI: 10.1080/01924788.2011.625218

[23] Kasser, T., Rosenblum, K. L., Sameroff, A. J., Deci, E. L., Niemiec, C. P., Ryan, R. M., Árnadóttir, O., Bond, R., Dittmar, H., Dungan, N., \& Hawks, S. (2013). Changes in materialism, changes in psychological well-being: Evidence from three longitudinal studies and an intervention experiment. Motivation and Emotion, 38, 1-22.

[24] Knickman, J. R., Snell, E. K. (2002). The 2030 Problem: Caring for Aging Baby Boomers. Health Services Research, $37,849-884$

[25] Lee, R. M., \& Robbins, S. B. (1998). The relationship between social connectedness and anxiety, self-esteem, and social identity. Journal of Counseling Psychology, 45, 338345 .

[26] Levy-Cushman, J., McBride, A., \& Abeles, N. (1999). Anxiety and depression: Implications for older adults. Journal of Social Distress and the Homeless, 8, 139-156.

[27] Lino VTS, Portela MC, Camacho LAB, Atie S, Lima MJB (2013) Assessment of Social Support and Its Association to Depression, Self-Perceived Health and Chronic Diseases in Elderly Individuals Residing in an Area of Poverty and Social Vulnerability in Rio de Janeiro City, Brazil. PLoS ONE 8(8): e71712. doi:10.1371/ journal.pone.0071712

[28] Longino, C. F., \& Kart, C. S. (1982). Explicating activity theory: formal replication. Journal of Gerontology, $35,713-22$. 
[29] Lucas, R. E., \& Donnellan, M. B. (2011). Personality development across the life span: Longitudinal analyses with a national sample from Germany. Journal of Personality and Social Psychology, 101, 847-861. doi: 10.1037/a0024298

[30] Maslow, A. H. (1954). Motivation and personality. New York, NY: Harper \& Row.

[31] Orth, U., \& Robins, R. W. (2014). The Development of Self-Esteem. Current Directions in Psychological Science, 23, 381-387.

[32] Orth, U., Robins, R. W., \& Widaman, K. F. (2012). Life-Span Development of Self-Esteem and Its Effects on Important Life Outcomes. Journal of Personality and Social Psychology, 102, 1271-1288.

[33] Orth, U., Trzesniewski, K. H., \& Robins, R. W. (2010). Self-Esteem Development From Young Adulthood to Old Age: A Cohort-Sequential Longitudinal Study. Journal of Personality and Social Psychology, 98, 645-658. DOI: 10.1037/a0018769

[34] Orth, U., Robins, R. W., Trzesniewski, K. H., Maes, J., \& Schmitt, M. (2009). Low Self-Esteem Is a Risk Factor for Depressive Symptoms From Young Adulthood to Old Age. Journal of Abnormal Psychology, 118, 472-478. DOI: $10.1037 / \mathrm{a} 0015922$

[35] Paradise, A. W., \& Kernis, M. H. (2002). Self-esteem and psychological well-being: Implications of fragile selfesteem. Journal of Social and Clinical Psychology, 21, 345361.DOI: http://dx.doi.org/10.1521/jscp.21.4.345.22598

[36] Ranzijn, R., Keeves, J., Luszcz, M., \& Feather, N. T. (1998). The Role of Self-Perceived Usefulness and Competence in the Self-Esteem of Elderly Adults: Confirmatory Factor Analyses of the Bachman Revision of Rosenberg's Self-Esteem Scale. Journal of Gerontology: PSYCHOLOGICAL SCIENCES, 53B. 96-104.

[37] Reinhardt, U. E. (2000). Heath Care for Baby Boom: Lessons from Aboard. Journal of Economic Perspectives, 14, 71-83.

[38] Robins, R. W., Tracy, J. L., Trzesniewski, K. H., Potter, J., \& Gosling, S. D. (2001). Personality correlates of selfesteem. Journal of Research in Personality, 35, 463-482.

[39] Robins, R. W., \& Trzesniewski, K. H. (2005). SelfEsteem Development Across the Lifespan. Current directions in Psychological Sciences, 14, 158-162.

[40] Robins, R. W., Trzesniewski, K. H., Gosling, S. D., Potter, J. (2002). Global Self-Esteem Across the life span. Psychology and Aging, 17.432-34. DOI: 10.1037//08827974.17.3.423

[41] Rosengren, K. E. (1974). Uses and gratifications: A paradigm outlined. In J. G. Blumler \& E. Katz (Eds.), The uses of mass communications: Current perspectives on gratifications research (pp. 269-286). Beverly Hills, CA: Sage

[42] Rowe, J.W., \& Kahn, R.L. (1997). Successful aging. The Gerontologist, 37,433-440.

[43] Scazufca, M., Menezes, P. R., \& Almeida, O. P. (2002). Caregiver burden in an elderly population with depression in São Paulo, Brazil. Soc Psychiatry Psychiatr Epidemiol, 37, 416-422.

[44] Schroots, J. J. F. (1996). Theoretical Developments in the Psychology of Aging. The Gerotological Society of America, 36, 742-748.

[45] Sermat, V. (1980). Some situational and personality correlates of loneliness. In J. Hartog, J. R. Audy. \& Y. A. Cohen (Eds), The anatomy of loneliness (pp. 305-318). New York: International Universities Press.

[46] Shaw, L. H., \& Gant, L. M. (2002). In defence of the Internet: The relationship between Internet communication and depression, loneliness, self-esteem, and perceived social support. CyberPsychology \& Behavior, 5, 157-171.

[47] Sum, S., Mathews, R. M., Hughes, I., \& Campbell, A. (2008). Internet Use and Loneliness in Older Adults. CyberPsychology \& Behavior, 11. 208-11. doi: 10.1089/cpb.2007.0010

[48] Sum, S., Mathews, R. M., Pourghasem, M., Hughes, I. (2009). Internet Use as a Predictor of Sense of Community in older people. CyberPsychology \& Behavior, 12, 235-39. DOI: $10.1089 / \mathrm{cpb} .2008 .0150$

[49] Sun, W. J., Xu, L., Chan, W. M., Lam, T. H. (2012). Depressive symptoms and suicide in 56,000 older Chinese: a Hong Kong cohort study. Soc Psychiatry Psychiatr Epidemiol, 47, 505-514. DOI: 10.1007/s00127-011-0362-z

[50] Tam, C.W.C. and Chiu, H.F.K. (2011) Depression and suicide in the elderly. The Hong Kong Medial Diary, Medical Bulletin, 16, 13-15.

[51] Tornstam, L. (1994). Gerotranscendence: A theoretical and empirical exploration. In L. E. Thomas \& S. A. Eisenhandler (Eds.), Aging and the religious dimension (pp. 203-226). Westport, CT: Greenwood.

[52] Tsang, J., Carpenter, T. P., Roberts, J. A., Frisch, M. B., \& Carlisle, R. D. (2014). Why are materialists less happy? The role of gratitude and need satisfaction in the relationship between materialism and life satisfaction. Personality and Individual Differences, 64, 62-66.

[53] Waite, P., McManus, F., \& Shafran, R. (2012). Cognitive behaviour therapy for low self-esteem: A preliminary randomizedcontrolled trial in a primary care setting. Journal of Behavior Therapy and Experimental Psychiatry, 43, 1049-1057. 
[54] Ward, R. A. (1977). The impact of subjective age and stigma on older persons. Journal of Gerontology, 32, 227 232.

[55] Wenger, G. C. (1997). Social networks and the prediction of elderly people at risk. Aging and Mental Health, 1, 311-320.

[56] Whitlock, L. A., McLaughlin, A. C., \& Allaire, J. C. (2012). Individual differences in response to cognitive training: Using a multi-modal, attentionally demanding game-based intervention for older adults. Computers in Human Behavior, 28, 1091-1096.

doi.org/10.1016/j.chb.2012.01.012

[57] World Health Organization. (2018). Mental health of older adults. [online] Available at: http://www.who.int/newsroom/fact-sheets/detail/mentalhealth-of-older-adults [Accessed 27 Nov. 2018].

[58] Yount, W. R. (2009). Transcendence and Aging: The Secular Insights of Erikson and Maslow. Journal of Religion, Spirituality \& Aging, 21, 73-89. DOI: 10.1080/15528030802265361

[59] Zickuhr, K., \& Madden, M. (2012). Older adults and Internet use: for the first time, half of adults age 65 and older are online. Pew Internet \& American Life Project. 